\title{
ARTICULAÇÃO INTERNACIONAL DOS ATINGIDOS PELA VALE NA LUTA CONTRA O CAPITAL E SUA FORMA DESTRUTIVA ${ }^{1}$
}

\author{
Maria Gorete de Sousa \\ Universidad Nacional de Córdoba
}

\section{ARTICULAÇÃO INTERNACIONAL DOS ATINGIDOS PELA VALE NA LUTA CONTRA O CAPITAL E SUA FORMA DESTRUTIVA}

Resumo: O artigo analisa a Articulação Internacional dos Atingidos pela Vale a partir da mobilização dos trabalhadores atingidos nas comunidades e cidades onde a empresa Vale tem atuação na sua forma destrutiva em impactos sociais, culturais e ambientais. Decorrente do intercâmbio com várias organizações, movimentos sociais e ambientalistas se inicia um processo de construção de uma rede internacional para troca de experiências visando acúmulo e discussão de ações conjuntas de ofensiva e resistencia à atuação da Vale nos diversos países. Essas articulações intentam afirmar que os liames da ofensiva e da resistência locais têm um imperativo: sua construção em escala continental, em perspectiva internacionalizada, posto que é este o circuito e a escala de operações do capital. Assim, no quadro da abordagem deste estudo, o artigo ressalta que a luta dos Atingidos pela Vale, não pode, historicamente, ser compreendida meramente no marco estrito da luta contra uma empresa e sua atuação. A compreensão se desborda, em esforço de síntese, na direção de uma luta para além da Vale. É a luta contra o capital e sua forma destrutiva.

Palavras-chave: Articulação Internacional dos Atingidos pela Vale, luta internacional, Capital.

\section{INTERNATIONAL ARTICULATION OF THOSE AFFECTED BY VALE IN THE FIGHT AGAINST THE CAPITAL AND ITS DESTRUCTIVE FORM}

Abstract: This paper analyzes the International articulation of those Affected by Vale from the mobilization of workers affected in communities and cities where the Vale Corporation operates in its destructive form in social, cultural and environmental impacts. Arising from the exchange with various organizations, social movements and environmentalists begins a process of building an international network to exchange experiences aiming accumulation and discussion of joint actions of offensive and resistance to the action of Vale in several countries. These articulations intend to to affirm that the bands of the offensive and the local resistance have an imperative: its construction on a continental scale,in internationalized perspective, since this is the circuit and operational scale of capital. Thus, under the approach of this study, the article highlights the struggle of People Affected by Vale can't historically be understood only in the context of the strict struggle against a company and its performance. An understanding overflows in synthesis effort, toward a struggle beyond the Valley. It is the struggle against capital and its destructive form.

Keywords: International articulation of People Affected by Vale, international struggle, Capital. 


\section{INTRODUÇÃO}

O foco deste trabalho é a análise da Articulação Internacional dos Atingidos pela Vale a partir da mobilização dos trabalhadores atingidos nas comunidades e cidades onde a empresa têm atuação, e cuja ação atinge de forma destrutiva toda a sociedade; portanto, o conceito de atingido perpassa a totalidade da sociedade, nos seus impactos sociais, culturais e ambientais.

Quando falamos de Articulação dos Atingidos pela Vale, estamos nos referindo, em específico, a um conjunto de movimentos sociais, sindicais, ambientalistas, comunidades e grupos organizados que buscam níveis de coesão coletiva com o objetivo de enfrentar os impactos causados pela ação da Vale.

No que se refere à relação entre a sociedade e a Vale, com a mediação do Estado, sendo que seu regime político é a democracia, ocorre que há uma fragilidade nessa regulação estatal, bem como nas obrigações da empresa Vale. Esse Estado democrático de direito é negado sistematicamente, quando se trata dos direitos dos que estão desprovidos, dos desvalidos, dos sem, como bem demonstra Silva:

\begin{abstract}
A marca do Estado brasileiro continua sendo a repressão aos movimentos sociais e/ou seletivamente aos membros das classes populares. Conforme ocorreu com as ligas camponesas em 1960, duramente reprimidas por reivindicar a reforma agrária, as lutas sociais dirigidas, por exemplo, pelo Movimento dos Trabalhadores Rurais Sem Terra, pelo Movimento dos Sem Teto ou pelo Movimento Atingidos por Barragens, recebem do Estado o mesmo tratamento autoritário. As mobilizações e as lutas sociais contra as políticas neoliberais são identificadas como ameaça ao Estado Democrático de Direito. (SILVA, 2012, p. 193).
\end{abstract}

Diante dessa tão evidente incongruência, os trabalhadores, camponeses, indígenas, ambientalistas, quilombolas irão questionar essa representação do Estado brasileiro, refazendo suas formas de resistências, agora diante de um novo quadro, pois não é atingida somente uma categoria de trabalhadores, são várias e, em vários lugares, ao mesmo tempo. Nesse passo, essas várias formas de resistências se juntam: as greves, ocupações, interdição da estrada de ferro, táticas cotidianas de resistir vão se construindo para que seus mínimos direitos não sejam denegados, dentro do Estado democrático de direito.

Por outro lado, o que se percebe é a violação dos direitos das populações locais onde se verifica a atuação da empresa Vale. Essa relação desigual e conflituosa entre a Vale e o Estado, por um lado, e os Movimentos Sociais, de outra parte, possibilitam a resistência local, mas, bem vistos os fatos e a construção, a perspectiva é internacional. O nível de repressão da Vale não difere quase em nada nos cinco continentes, como podemos constatar entre as experiências do Canadá, Moçambique, Perú e Brasil, quando se examina o problema em perspectiva comparada.

\section{VIOLAÇÃO DOS DIREITOS E RESISTÊNCIA DAS POPULAÇÕES LOCAIS ONDE SE VERIFICA A ATUAÇÃO DA EMPRESA VALE}

Constitui caracteristica comum no modo de atuação da Vale nos diferentes países, na forma de impedir que os atingidos reivindiquem seus direitos; em primeiro lugar, sua estrita ligação com o Estado nesses países. No caso do Canadá, a Vale encontrou maiores dificuldades para flexibilizar a legislação local; entretanto as formas diversas e simultâneas de persuasão, pressão, cooptação, são de natureza idêntica em todos os países.

Segundo depoimento de um sindicalista mineiro do Canadá, entre os anos de 2009 e 2010 , na Vale-Inco ${ }^{2}$, a política da empresa inicia um amplo processo de redução dos salários, aumento das jornadas de trabalho, demissões massivas, e, principalmente, o corte de benefícios e outros direitos adquiridos. Tal política de denegação de direitos encontrou uma forte resistência dos trabalhadores, como se observa na realização da maior greve já ocorrida no Canadá: 12 meses em Sudbury, Port Colborne e Ontário; 18 meses em Voisey's Bay, na Província de Newfoundland e Labrador, mobilizando mais de três mil trabalhadores. O fato mais marcante desse processo é que desencadeou uma rede de solidariedade, envolvendo não somente a categoria dos mineiros, ultrapassando as categorias e fronteiras de países e continentes, amadurecendo, dessa forma, o processo de articulação internacional dos atingidos pela Vale.

Ainda em depoimento, o sindicalista canadense, no I Encontro Regional dos Atingidos pela Vale (2011), após o contato com os relatos de brasileiros e moçambicanos sobre os impactos que a Vale tem causado, conclui: "No Canadá, a forma como a Vale está impondo aqui e na África, seria diferente, não seria tão aberto, mas no final seria feito".

A riqueza da experiência vivida entre os atingidos pela Vale aprofunda essa compreensão da luta para além de suas comunidades, de suas fronteiras. A troca de informações, o intercâmbio entre as experiências que são contadas, socializadas nos momentos de vivência prática dos mineiros canadenses em outros países e dos trabalhadores em apoio ao Canadá, fortalecem o sentimento de coesão coletiva e horizonte comum, o que possibilita 
pensar uma luta internacional, a princípio, contra uma empresa. Essa notável troca de experiências tornase um elemento fundante, no sentido da construção de laços mediante a experiência da exploração de vários rostos e culturas, mas sob o mesmo capital.

Outras formas de resistência onde se observa um conteúdo comum serão experimentadas em outras partes do mundo, como é o caso dos megaprojetos de mineração de Moma e Moatize para abertura das minas de carvão, no Norte e Centro de Moçambique. Segundo denúncia do Centro Moçambicano de Integridade Pública, de 2009 até o momento, muitos camponeses foram expulsos de suas comunidades, cerca de 760 famílias, quando a Vale criou projetos de reassentamentos para as famílias. Contudo, essas comunidades vivem um agudo grau de expropriação: de "seu território", de sua cultura, de sua história ancestral e do tempo presente, bem como de suas formas de produzir a existência na agricultura, agravando ainda mais os níveis de pobreza na região (CAMPOS, 2006; GALAFASSI, 2012).

Outros casos de resistência provocados sempre pelos impactos sociais e ambientais ocorrem em comunidades vulneráveis e com uma ausência da ação do Estado, como nos casos do Perú na região de Cajamarca, na Indonésia, na Argentina e na Nova Caledônia. São lutas de resistência às formas de atuação violenta da Vale, com a ação de milícias dentro das instalações, perseguição às lideranças, disputa de terras em regiões onde havia lavouras, casas, cemitérios, agora desvestidos de seu significado e existência concreta e transformados em canteiros de obras e lugares da produção e extração dos minérios.

A confluência dessas lutas se dá pela natureza das mesmas, atingindo ao mesmo tempo trabalhadores dos cinco continentes nas formas de exploração do trabalho e bens da natureza. Esse fato social possibilita a articulação de uma linguagem comum da luta social, no encontro desde a exploração e expropriação de milhares de trabalhadores, camponeses, populações tradicionais, povos indígenas na resistência local; favorecendo, entretanto, níveis de compreensão e exigência de uma ofensiva internacional, explicitada pela própria realidade, sem mediações. Há em curso um processo de lutas de resistência em defesa do que os movimentos sociais, comunidades tradicionais e indígenas chamam de bens comuns da natureza.

Podem-se enumerar vários casos da forma como a Vale vai atuar junto às comunidades, no sentido do convencimento, da persuasão, cujo efeito é a criação de mecanismos de colaboração com os objetivos imediatos ou de largo prazo da empresa. Tal se observa nos casos do Assentamento Palmares, em Parauapebas, estado do Pará e Açailândia (Maranhão), onde 18 militantes do MST foram condenados com uma ação de Interdito
Proibitório $^{3}$ impetrado pela Vale, ou estão sob vigilância, com inquérito policial. A ação de interdito determina que os militantes sociais sejam proibidos de se aproximar 500 metros dos trilhos da ferrovia. A alegação da empresa visa, segundo a medida, impedir a ameaça de ocupação dos trilhos da Estrada de Ferro de Carajás; nesse caso, é de se anotar o pleno desconhecimento da vida nestas comunidades, pois elas vivem nas áreas por onde passa o trem. Necessitando ir e vir todos os dias para trabalhar, os trabalhadores se veem na situação de presos em sua própria casa, em sua comunidade. $\mathrm{O}$ eufemismo da linguagem autoritária da empresa tem como lastro a definição de responsabilidade, ou seja, como qualquer manifestação de resistência cujo lugar seja os trilhos da EFC e de responsabilidade desses militantes, transformados em suspeitos, a linguagem judicializada recorre ao termo de ação preventiva. São fatos dessa natureza que corroboram a necessidade de luta unificada dos atingidos pela Vale.

No obstante, este intento de "alienación territorial" (SANTOS, 1996) enfrenta radicales y masivas resistencias locales que, mediante la conformación de redes de solidaridad $-y$ el auxilio de las tecnologías de la información-, se han propagado a nivel nacional y continental, dando lugar a la configuración de un "nuevo internacionalismo". (SEOANE, TADDEI; ALGRANATI, 2006).

A empresa Vale se utiliza dos instrumentos do Estado para reprimir e coibir qualquer tipo de mobilização reivindicatória, contraditoriamente ao previsto no Estado democrático de direito e na própria argumentação da Vale. Retomamos o seu slogan somos globais porque estamos em todo o mundo, somos globais porque pensamos no mundo todo, para atestar a inversão do discurso, se confrontado, com a prática empresarial, afirmando de forma global um jeito de coagir, cooptar, explorar e expropriar. De outra parte, essa prática vai provocar uma rede de solidariedade internacional, possibilitando que os atingindos pela ação predatória da empresa Vale possam também, de forma global, construir uma resistência e ofensiva na perspectiva dos movimentos sociais.

Essa articulação foi sendo construída a partir de outros espaços de mobilização internacional de movimentos de luta contra o neoliberalismo, de fundo anti-imperialista e anticapitalista; entre esses espaços, está o FSM (Forum Social Mundial) ${ }^{4}$. Sua nona edição, realizada em Belém, capital do Pará, foi um momento de grande debate sobre a situação da Amazônia, quando a Via Campesina organiza uma atividade preparatória ao FSM - uma caravana internacional pela Amazônia, cujo objetivo seria aprofundar o conhecimento sobre os problemas e os enfrentamentos ao capital na região. Naquele momento a Vale se destaca como um 
investimento do capital que muito tem impactado as populações da região.

Fruto desse intercâmbio com várias organizações, movimentos sociais, ambientalistas se inicia um processo de construção de uma rede internacional para troca de experiências em acúmulo e discussão de ações conjuntas de ofensiva e resistencia à atuação da Vale em seus países. Nesse primeiro momento é pensado um Primeiro Encontro, quando se organizariam de modo articulado as diferentes denúncias, visando, sobretudo, ampliar as formas de solidariedade entre os atingidos, como bem expressos em seu documento convocatório.

\begin{abstract}
A articulação dos povos e movimentos nos diferentes países em que há exploração da mineradora é fundamental para fortalecer nossas lutas locais, nacionais e internacionais. Precisamos nos unir para construirmos juntos nossas estratégias, e pressionarmos nossos governos para que nossos direitos de vida, trabalho, terra, moradia, saúde, e de um ambiente justo e saudável sejam garantidos. (Documento Convocatório, 2010).
\end{abstract}

Essa compreensão internacional da luta social se afirma frente às possibilidades que (re) surgem na organização dos trabalhadores e acordes à singularidade de cada período histórico. No atual momento, a afirmação da luta internacional é condição para se pensar soluções, respostas, às questões que foram impostas pelo modo de produção capitalista. Nesse passo, os Encontros de base internacional, as articulações intentam afirmar que os liames da ofensiva e da resistência locais têm um imperativo: sua construção em escala continental, em perspectiva internacionalizada, posto que é este o circuito e a escala de operações do capital.

A realização do I Encontro da Articulação Internacional dos Atingidos pela Vale foi um marco importante, pois ali se materializa a necessidade objetiva de união e coesão social de diferentes categorias de trabalhadores, movimentos sociais e ambientalistas, sob um objetivo comum: denunciar a política agressiva e predatória da Vale, socializar experiências de luta social e estabelecer formas de cooperação e solidariedade, como afirmado em Relatório desse primeiro Encontro.

Nesse sentido, o ano de 2010 marca significativamente um novo momento na articulação dos trabalhadores e atingidos da Vale, quando é realizado o Primeiro Encontro Internacional dos Atingidos pela Vale, em abril de 2010, no Rio de Janeiro, com a participação de representantes de organizações sindicais e movimentos sociais dos seguintes países: Brasil, Canadá, Chile, Argentina, Guatemala, Peru, Nova Caledônia e Moçambique,
Este encontro visa articular e consolidar uma rede de movimentos sociais, organizações e centrais sindicais de diversos países, incluindo populações, comunidades e trabalhadores(as) atingidos negativamente na suas formas de vidas e nos seus direitos pela forma de atuação da Vale, capaz de implementar estratégias coletivas de enfrentamento à empresa em escala global. Ao longo dos últimos anos, inúmeras experiências mostraram que, para enfrentar os impactos e as violações causadas pela Vale, é necessária uma articulação global (Dossiê dos Impactos e Violações da VALE no Mundo, p.11, mimeo).

A finalidade do Encontro, segundo nota convocatória, eradefinirestratégiascomuns detrabalho com o objetivo de fortalecer a luta dos trabalhadores e comunidades atingidas negativamente. Além disso, as entidades participantes enfatizam que a união popular de pressão destina-se a fazer com que a Vale

[...] cumpra mundialmente com os padrões ambientais, tecnológicos e trabalhistas elevados, e que respeite e não tente retroceder as legislações vigentes. Não vamos deixar que a Vale rebaixe nossos direitos conquistados e destrua nossas vidas. (Documento Convocatório, 2010).

O que marca como característica de lutas, nesse tipo de organização, é a combinação entre o enfrentamento direto e, ao mesmo tempo institucional. A luta direta que se dá na resistência diária e que surge como movimento e reação local e ofensiva das comunidades, havendo, desta forma, uma aproximação dos significados das lutas no Brasil, África, Ásia e América. Assim, tomam formas de lutas sociais em defesa de seus territórios; aqui se dá o que se chama de resistência e ofensiva como possibilidades de um movimento emancipatório.

A atuação da Articulação Internacional dos Atingidos pela Vale é autônoma e plural, buscando dar visibilidade internacional à luta, caminho e possibilidade de avançar na luta por direitos em todos os países com atuação da Vale. O fazer dessa luta utiliza duas ferramentas, como dito anteriormente: o enfrentamento direto e as ações institucionais; desde as mobilizações na Estrada de Ferro de Carajás, ocupações, até a participação nas assembleias de acionistas da empresa Vale.

Entretanto, percebe-se que embora tenha avançado na quantidade de denúncias, na capacidade de mobilização é ainda considerado um limite, pelas comunidades atingidas, o nível de conquistas. Em alguns países não se avançaram em conquistas, embora não haja perda de direitos; entretanto, na maioria dos países da América Latina, África e Ásia, além dos trabalhadores perderem 
seus minguados direitos, também os camponeses e indígenas perderam seus territórios.

\section{CONCLUSÃO}

O capital, na atualidade, assume uma essência expansiva e destrutiva, melhor dizendo, a lógica da produção destrutiva que Mészáros (2009) identifica como um dos sintomas da atual crise do sistema. O autor afirma que não é possível ajustar o capitalismo; é de sua natureza que essa crise não se resolva do seu interior; tem que ir além do modo de produção capitalista. Portanto, um novo patamar para a acumulação e para a subsunção do trabalho é resultado de sua natureza irreversivelmente destrutiva e incompatível com as necessidades da humanidade.

Assim, no quadro da abordagem deste estudo, é de se ressaltar, em conclusão, que a luta dos Atingidos pela Vale, não pode, historicamente, ser compreendida no marco estrito de luta contra uma empresa e sua atuação. A compreensão se desborda, em esforço de síntese, na direção de uma luta para além da Vale. É a luta contra o capital e sua forma destrutiva. Essa articulação internacional possibilita um tipo de ação necessária no atual momento histórico, para propor alternativa à lógica dominante de acumulação destrutiva expressa nos grandes projetos de mineração espalhados pelo mundo. Retomar, em nosso tempo presente, o sentido do internacionalismo como resistência e ofensiva contra o capital é um imperativo como condição para continuar a reprodução da vida.

Ao final, queremos reafirmar, em perspectiva, a escrita de alerta do Manifesto Comunista, de Marx e Engels, em 1848, acerca da alternativa histórica para o proletariado: sua união em todo o mundo contra a exploração capitalista. O Manifesto é aqui atualizado, em sua dimensão de escrita de convocação à luta incessante contra um sistema de desigualdades e injustiças, baseado na opressão e exploração dos trabalhadores, o sistema capitalista e suas iniquidades. O Manifesto, como escrita de aviso, é uma indicação histórica do sujeito revolucionário: "Os proletários nada têm a perder a não ser suas algemas. Têm um mundo a ganhar"; é uma escrita do internacionalismo operário e de conclamação á luta social, como bem expressa sua frase final, tão conhecida e tão atual: Trabalhadores de todo o Mundo, Uní-vos!

Essa consigna, como se vê nas questões examinadas neste trabalho, é atualizada, é contemporânea, e se coloca como imperativo para se pensar um mundo de justiça e liberdade.

\section{REFERÊNCIAS}

CAMPOS, André. Babaçu livre. [S. I.: s. n.], 2011. Disponível em: <http://www.reporterbrasil.com.br>. Acesso em: 29 ago. 2011.
GALAFASSI, Guido. Modos de acumulación, recursos naturales y dominio colonial en América Latina. Un intento de mirada crítica sobre la "reinvención" del modelo extractivo. Revista THEOMAI, Buenos Aires, n. 25, p. 1-2, 2012. Disponível em: <http:// www.revista-theomai.unq.edu.ar/numero25/Intro. pdf>. Acesso em: 10 ago. 2012.

\section{ENCONTRO INTERNACIONAL DOS ATINGIDOS} PELA VALE. Dossiê dos Impactos e Violações da Vale no Mundo. Rio de Janeiro, 2010.

\section{MÉSZÁROS, István. A crise estrutural do capital.} São Paulo: Boitempo, 2009.

SEOANE, José; TADDEI, Emilio; ALGRANATI, Clara. Las nuevas configuraciones de los movimientos populares en América Latina. In: BORON, Atilio; LECHINI Gladys (Orgs.). Política y movimientos sociales en un mundo hegemónico: lecciones desde África, Asia y América Latina. Buenos Aires: CLACSO, 2006.

SILVA, Ilse Gomes. O Estado Burguês no Brasil sob suspeita: democracia e participação política no momento atual. Revista de Políticas Públicas, São Luís, v. 14, n. especial, p. 191-196, 2012.

VIA CAMPESINA BRASIL. A ofensiva da direita: para criminalizar os movimentos sociais no Brasil. Porto Alegre: Forúm Social Mundial, 2010.

\section{NOTAS}

1 Uma versão deste texto se encontra na dissertação de Mestrado: Um Estudo sobre a Resistência e Ofensiva na luta dos Atingidos pela Vale: nos caminhos dos trilhos no Maranhão, defendida na UNIFESP em fevereiro 2013, com orientação de Dr. Javier Amadeo.

2 Subsidiária da Vale, tem um processo impetrado pelas comunidades locais por problemas ambientais por destruir o Lago de Sandy Pond. Embora tenha sido condenada em 2010 ao pagamento de cerca de 36 milhões de dólares canadenses em indenização para mais de 7.000 (sete mil) moradores de Port Colborne (Província de Ontario), a Vale conseguiu nova análise do caso, este, em nível da Suprema Corte do Canadá.

3 É uma ação proibitória quando uma pessoa, ou grupo de pessoas não pode se aproximar de uma propriedade, sob alegação de que o proprietário está sendo ameaçado. É uma ação de natureza preventiva, desdobrada da ação de manutenção de posse (em conversa informal com uma advogada da Terra).

4 Surge como contraponto ao Fórum Econômico Mundial, que ocorre anualmente em janeiro, em Davos, na Suíça. O FSM ocorre desde o ano de 2001, 
as primeiras versões tiveram lugar em Porto Alegre (2001, 2002, 2003, 2005 e 2009) ainda no Brasil, foi realizada em 2009 em Belém, no Pará.

\section{Maria Gorete de Sousa}

Pedagoga

Doutoranda em Estudios Sociales Agrários na Universidad Nacional de Córdoba - Argentina.

Educadora da Escola Nacional Florestan Fernandes ENFF

Email:mariagorete@enff.org.br

\section{Escola Nacional Florestan Fernandes - ENFF}

Rua Jose Francisco Rapozo, Parateí

08900000 - Guararema, SP - Brasil 